\title{
Evaluation of Large-Scale Rapid Antigen Testing of Incoming Passengers at a Dynamic Point of Care Setting Carried Out by Dental Students for Covid-19 Screening - A Field Report
}

\author{
Akshay K. Langalia' ${ }^{1}$, Dolly P. Patel2 ${ }^{2}$, Aravind D. Kumbhar ${ }^{3}$, Hetal J. Maheshwari ${ }^{4}$, \\ Shubhangi K. Vyas ${ }^{5}$, Parishi K. Marfatia ${ }^{6}$, Yash M. Lalwani ${ }^{7}$, Aarshvi A. Shah ${ }^{8}$ \\ 1,3,4,5,6 Department of Conservative Dentistry \& Endodontics, AMC Dental College, Near Bhalakiya Mill \\ Compound, Khokhra, Ahmedabad, India, 2,7,8 Department of Orthodontics, AMC Dental College, Near \\ Bhalakiya Mill Compound, Khokhra, Ahmedabad, India
}

\section{ABSTRACT}

\section{BACKGROUND}

Assessment of the results of large-scale rapid antigen diagnostic (RAD) testing for detection of SARS-CoV-2 amongst incoming passengers was carried out by Ahmedabad Municipal Corporation (AMC) Dental College Students at the Central Railway Station of Ahmedabad city. We wanted to determine the sensitivity and specificity of RAD testing for detection of Covid-19 amongst passengers disembarking from scheduled trains arriving at the Central Railway Terminus of Ahmedabad city.

\section{METHODS}

Under the campaign "Chase the Virus" launched by Ahmedabad Municipal Corporation (AMC), Interns \& Final Year students of AMC Dental College were trained to carry out rapid antigen testing of scheduled trains running on special routes starting from 07 / 09 / 2020 to 05 / 10 / 2020. 14 dental teams were deputed at a temporary testing facility formulated for day-to-day testing at the Central Station using the standalone Standard - Q Covid-19 Ag testing kit (SD Biosensor, South Korea).

\section{RESULTS}

In total, 18901 travellers were tested in a span of 26 days out of which 324 tested positive with an overall percentage positivity of $1.71 \%$. An average number of 727 $( \pm 182)$ tests were performed with an overall sensitivity of $66.01 \%$ and specificity of $99.71 \%$.

\section{CONCLUSIONS}

In response to the growing Covid-19 pandemic and complexity of laboratory-based molecular tests, rapid antigen detection tests have proved to be efficient in the easier and faster diagnosis of the passengers in such point of care settings.
Corresponding Author: Dr. Akshay K. Langalia, E-1004, Parishkar-2, Phase-2, Khokhra, Ahmedabad-380008, India.

E-mail: akshaylangalia@gmail.com

DOI: $10.14260 /$ jemds/2021/558

How to Cite This Article:

Langalia AK, Patel DP, Kumbhar AD, et al. Evaluation of large - scale rapid antigen testing of incoming passengers at a dynamic point of care setting carried out by dental students for covid - 19 screening - a field report. J Evolution Med Dent Sci 2021;10(33)2734-2739, $10.14260 /$ jemds $/ 2021 / 558$

Submission 17-03-2021,

Peer Review 03-06-2021,

Acceptance 09-06-2021,

Published 16-08-2021.

Copyright (C) 2021 Akshay K. Langalia et al This is an open access article distributed under Creative Commons Attribution License [Attribution 4.0 International (CC $B Y 4.0)]$

\section{KEY WORDS}

Rapid Antigen Detection Test, Covid-19, SARS-CoV-2 


\section{BACKGROUND}

In December 2019, pneumonia of an unknown origin (later called coronavirus disease 2019, Covid-19) was identified in Wuhan, China. ${ }^{1-4}$ Rapid spread of the newly discovered SARS$\mathrm{CoV}-2$, the seventh member of the coronaviridae family ${ }^{5}$ escalated the concerns of the World Health Organization (WHO) declaring Covid-19 as a global pandemic in March 2020.6 Primarily, described as an upper \& lower respiratory tract infection due to human - to - human contact, several countries around the world had to implement immediate measures to curb further spread of the disease. ${ }^{7}$

Various strategies like total shutdown and travel restrictions were imposed by different governments, India not being an exception implemented a nationwide lockdown on 24th March $2020 .{ }^{\text {th }}$ The lockdown in India was implemented in four phases starting from $25^{\text {th }}$ March 2020 to $31^{\text {st }}$ May 2020 restricting travel via all public and private modes of transportation routes including railways and airways. ${ }^{9}$ Indian railways had suspended passenger mail and express train services from March $25^{\text {th }}$ amidst the nationwide lockdown. ${ }^{8}$

However, special guidelines were issued by the Ministry of Home Affairs (MHA) to facilitate limited movement of trains for domestic travel and transit of migrant workers, students, pilgrims and tourists by operating Shramik special trains from May 2020 followed by running approximately 100 pairs of timetabled trains from June $2020 .{ }^{10}$ To avoid overcrowding at the stations, the centre released standard operating procedures (SOP) to ensure appropriate social distancing and compulsory screening of the passengers. ${ }^{11}$ Simultaneously, Ahmedabad Municipal Corporation (AMC) from Gujarat State Administration launched the campaign called "Chase the Virus" on $01-07$ - 2020 in an attempt to combat the virus by testing, identifying, isolating asymptomatic as well as symptomatic carriers of Covid-19.12

Along with the recommencement of Metro Rail Services from $7^{\text {th }}$ September 2020,13 as per the guidelines issued in Unlock 4.0, concurrently on the same day itself, the Ministry of Health, AMC formulated a testing facility at the central railway station of Ahmedabad city to perform rapid antigen screening of incoming passengers to effectively isolate symptomatic individuals thereby blunting the further spread of the virus. Although reverse-transcription polymerase chain reaction (RT - PCR) is considered to be the gold standard for the detection of Covid-19, the requirement of specialized instruments, laboratory facilities and expertise pause a restriction in its usage in point of care settings. In contrast, rapid antigen detection immunoassays (RAD) that can be quickly performed and easily analysed, are cheap and enhance turnaround times. ${ }^{14}$ Furthermore, an improved correlation between the infectiousness of the patient especially in the initial days of infection and the results of antigen assay has been observed recently as compared to RT - PCR results. ${ }^{15}$

Very few studies depicting the use of standalone antigen kits for screening Covid-19 have been published in an ancillary testing facility near a railway transit station. Therefore, the purpose of this study was to describe the protocol and assess the use of Standard - $Q$ Covid-19 Ag antigen kit (SD Biosensor, South Korea), carried out by dental students who were extensively trained in the state of need.

\section{METHODS}

This cross-sectional study was approved by the Institutional review board of AMC Dental College (AMC / IRB / STAFF01 / 20). Under the aegis of MOH - AMC, the Dean of AMC Dental College was directed to form 14 dental teams to conduct rapid antigen testing of incoming passengers at the central railway station, Ahmedabad City from $7^{\text {th }}$ September 2020 to $5^{\text {th }}$ October 2020. Consequently, 14 teams each comprising of two well trained dental students and one helper staff was formulated. Further four faculties of the institute were appointed by the authorities as coordinators to supervise the teams and ensure unequivocal functioning.

\section{RESULTS}

\section{Training at the Institution}

All the appointed 195 students, 47 subordinate staff as well as four coordinators were thoroughly trained by expert medical professionals of AMC affiliated medical colleges and hospitals by conducting a full day extensive training session. The training commenced with an onscreen presentation on a brief view of Covid-19, rapid antigen test and the conventional way of wearing all the personal protective gears was shown. They elaborated and practically demonstrated the entire protocol right from handling and interpreting the Standard - Q Covid19 Ag antigen kit (which had a sensitivity of $96.52 \%$ and a specificity of $99.68 \%$ as claimed by the manufacturer) and taking nasopharyngeal swab samples. Instructions were also given on donning and doffing of PPE's, basic examination of the patient and recording the history according to the format designed by $\mathrm{MOH}$ - AMC as per the Indian Council of Medical Research (ICMR) guidelines. The helper staff were explained in their regional language on assisting the students about the proper disposal of the kits and other bio-medical waste as well as helping them in any way possible.

\begin{tabular}{|ccc|}
\hline Name of the Train & Time Slot & Day \\
Rajdhani Express & $8: 00$ am to $2: 00 \mathrm{pm}$ & Monday to Saturday \\
Nizamuddin Express & $3: 00 \mathrm{pm}$ to $7: 00 \mathrm{pm}$ & Monday to Saturday \\
Gorakhpur Express & $3: 00 \mathrm{pm}$ to $7: 00 \mathrm{pm}$ & Monday to Saturday \\
Howrah Express & $8: 00$ am to $2: 00 \mathrm{pm}$ & Sunday \\
\hline \multicolumn{2}{|c|}{ Table 1.Trains Allotted by $\mathbf{M O H}-$ AMC on $\boldsymbol{a}$ Weekly Basis } \\
\hline
\end{tabular}

\section{Duty Allocation}

AMC had set up an onsite testing facility near the exit gate of the Central Railway Station. All incoming travellers had to get mandatorily tested as per the regulations set by the Ministry of Railways (MOR) and MOH - AMC. All the students who received the training were assigned duties, as per the list allotted to coordinators by MOH - AMC on the day-to-day basis, except six students who were spared because of their health conditions after due permissions from the assigned medical board. All dental teams were sent on each day for conducting rapid antigen detection (RAD) in either of the two slots: 8 am to $2 \mathrm{pm}$ and $2 \mathrm{pm}$ to $8 \mathrm{pm}$. The slot wise everyday distribution of arriving trains from $7^{\text {th }}$ September 2020 to $5^{\text {th }}$ October 2020, during which the dental students were appointed for the duty 
is graphically represented and tabulated in Table 1 and Table 2.

\section{Testing}

The exiting passengers were screened and directed towards the testing facility and were queued with appropriate social distancing and masks. For every individual, one of the two team members would record all the necessary details in the testing form including personal information, a complete history and their categorization according to ICMR guidelines and then assign a sample number. Any passenger exhibiting three or more of the enlisted clinical symptoms in the history form was considered as a potential "clinically COVID positive" individual. The other team member would cross verify the latter and then perform the RAD test following the ICMR guidelines. ${ }^{16}$

1. After explaining to the patient about the procedure and marking the testing strip with the sample number assigned before, the nasopharyngeal swab from both the nostrils was collected with the customized sample collection swab provided with the kit.

2. The swab stick was then dipped and squeezed in the viral extraction buffer, provided with the kit thereby inactivating the virus.

3. Considering the viability of the collected sample to be an hour, the buffer along with the swab was mixed instantaneously.

4. The buffer tube cap was then replaced with a nozzle and 2 - 3 drops of the mixed buffer solution were dispensed into the testing well of the strip. The exact time at this point was noted in the testing form. The test could be interpreted as positive or negative depending upon the appearance of test and control lines in a minimum of 15 minutes and a maximum of 30 minutes after which the test strip had to be discarded. ${ }^{16,17}$

\begin{tabular}{|ccc|}
\hline Date & \multicolumn{2}{c|}{ Number of Train } \\
$07 / 09 / 2020$ & $8: 00 \mathrm{am}$ to $2: 00 \mathrm{pm}$ & $3: 00 \mathrm{pm}$ to $7: 00 \mathrm{pm}$ \\
$08 / 09 / 2020$ & 1 & - \\
$09 / 09 / 2020$ & 1 & - \\
$10 / 09 / 2020$ & 1 & - \\
$11 / 09 / 2020$ & 1 & - \\
$12 / 09 / 2020$ & 1 & - \\
$13 / 09 / 2020$ & 1 & - \\
$14 / 09 / 2020$ & 1 & - \\
$15 / 09 / 2020$ & 1 & - \\
$16 / 09 / 2020$ & 1 & - \\
$17 / 09 / 2020$ & 1 & 2 \\
$18 / 09 / 2020$ & - & 2 \\
$19 / 09 / 2020$ & - & 2 \\
$21 / 09 / 2020$ & - & - \\
$22 / 09 / 2020$ & 1 & - \\
$23 / 09 / 2020$ & 1 & - \\
$24 / 09 / 2020$ & 1 & - \\
$25 / 09 / 2020$ & 1 & - \\
$26 / 09 / 2020$ & 1 & - \\
$28 / 09 / 2020$ & 1 & 2 \\
$29 / 09 / 2020$ & 1 & 2 \\
$30 / 09 / 2020$ & 1 & 2 \\
$01 / 10 / 2020$ & 1 & 2 \\
$02 / 10 / 2020$ & 1 & 2 \\
$03 / 10 / 2020$ & 1 & 2 \\
$05 / 10 / 2020$ & 1 & 2 \\
\hline Table 2 Number of Trains Allotted Vs. Date \\
\hline \multicolumn{2}{c}{ Num } \\
\hline
\end{tabular}

\section{Interpretation of the Test}

The test results were interpreted as positive, negative or invalid based on lines at both $\mathrm{C}$ and $\mathrm{T}$ areas, a single line at only $\mathrm{C}$ area or no lines respectively. Those individuals who turned out to be positive in the RAD test were stamped on their hands with an indelible ink by the first team member and were then referred to the onsite medical officer (MO) for further quarantining and necessary treatment. Individuals who were symptomatic and turned out to be negative on the test were referred to the attending medical officer to recommend him / her for RT - PCR testing.

\section{Statistical Analysis and Results}

To facilitate constant communication, a WhatsApp group of all the team members and appointed faculty coordinators was formed. The assigned team leaders of each of the 14 teams were instructed to forward all the details of daily recorded passengers in a dedicated format designed by the coordinators of AMC Dental College on an everyday basis. Based on the received information, the coordinators would tabulate the data in Microsoft Excel (MS office 2019) format. Descriptive statistics of the collected data was performed, mean and standard deviations were deduced.

A total of 18901 passengers were tested between $7^{\text {th }}$ September 2020 to $5^{\text {th }}$ October 2020 (total testing days: 26 Days). On an average $727( \pm 182)$ tests were performed by the 14 appointed dental teams and an average number of $12( \pm 8)$ travellers were screened to be positive by RAD tests. The daily distribution of the total number of samples taken and total positives is represented in Graph 2 \& Graph 3. Further, the overall percentage positive rate of the total number of tests carried out by dental teams was found to be $1.71 \%$. Based on information obtained from the recorded history sheets which were used to identify the "Clinically COVID positives" and the individuals who were onsite positive with RADs and designated as "Test positives", a 2X2 contingency table was prepared. Clinically COVID positives were defined as those having any three symptoms from the enlisted i.e. fever, shortness of breath, cough, generalized weakness / body ache, loss of smell/taste, diarrhoea according to the antigen testing categorization designed by MOH-AMC.

Wilson score method was used to analyse the data and determine the sensitivity and specificity which resulted in an overall sensitivity of $66.01 \%$ and specificity of $99.71 \%$ (table 3). Also, a positive predictive value of $83.33 \%$ and a negative predictive value of $99.25 \%$ could be deduced. The diagnostic accuracy of RAD tests turned out to be $98.98 \%$ in our study. The overall performance of each dental team on a single testing day was found to be on an average of 52 tests / day.

\begin{tabular}{|cccc|}
\hline Test Result & Clinically Positive & $\begin{array}{l}\text { Clinically } \\
\text { Negative }\end{array}$ & Total \\
Test positive & 270 & 54 & 324 \\
Test negative & 139 & 18438 & 18577 \\
Total & $\mathbf{4 0 9}$ & $\mathbf{1 8 4 9 2}$ & $\mathbf{1 8 9 0 1}$ \\
Sensitivity & $66.01 \%$ & \\
Specificity & $99.71 \%$ \\
\hline \multicolumn{3}{|c|}{ Table 3. 2 * 2 Contingency Table Determining the } \\
& Sensitivity and Specificity \\
\hline
\end{tabular}



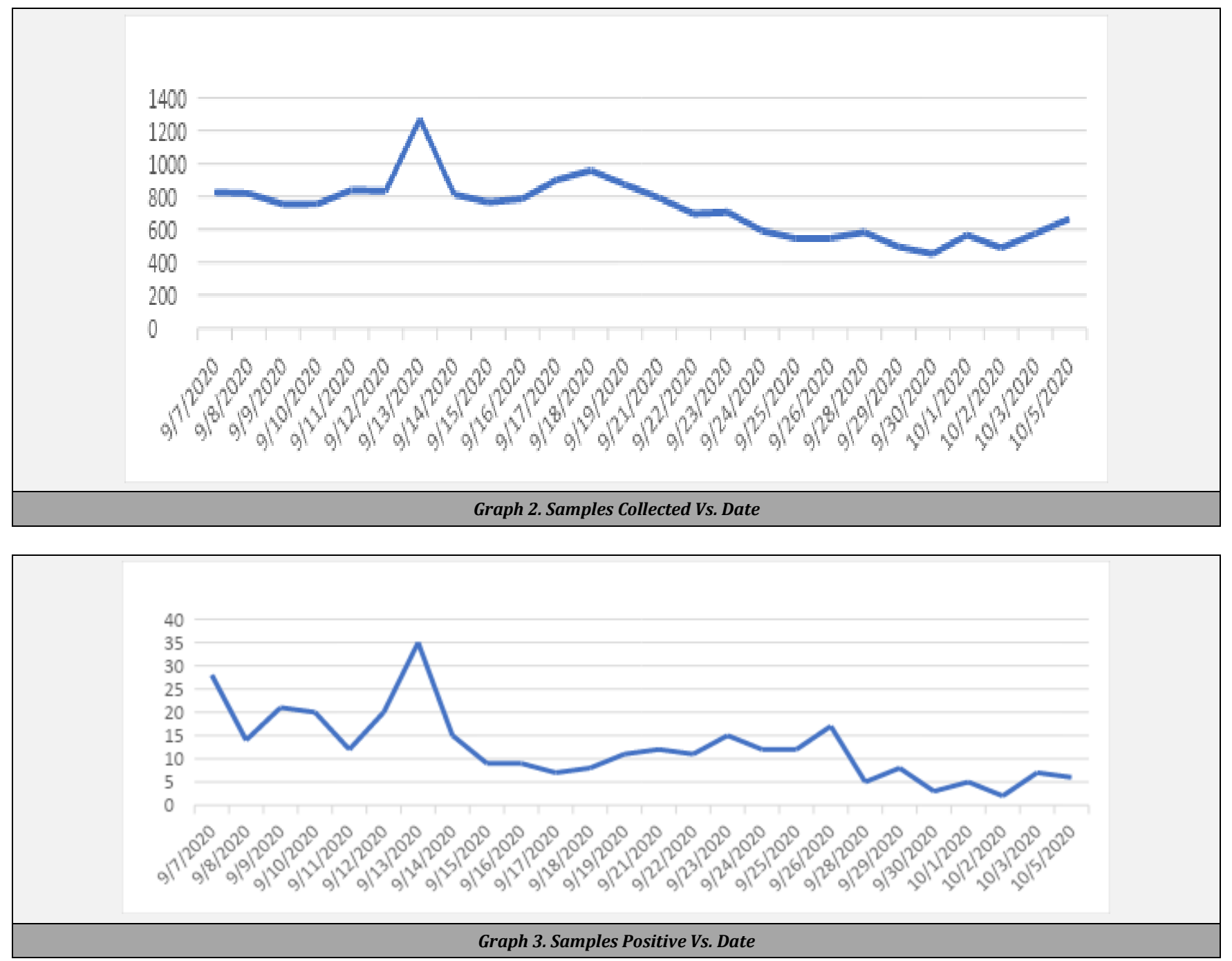

\section{DISCUSSION}

Rapid screening and accurate diagnosis for the detection of SARS-CoV-2 are of paramount importance in dynamic, highly crowded settings like Railroad terminus for easy identification, effective isolation and early quarantining of infected individuals. The guarded use of RAD tests has been attributed to its lower sensitivity although it is important to understand that it depends on several factors like viral load, sample type, time from illness onset and setting of patients tested. ${ }^{18}$ In the study carried out by Anais Scohy et al. they demonstrated a low overall sensitivity of $30.2 \%$ amongst 148 nasopharyngeal samples collected. ${ }^{19}$ Interestingly, another study was carried out by Gannon CK Mak et al. in which RAD tests exhibited an extremely variable sensitivity detecting between $28.6 \%$ and $81.8 \%$ of RT - PCR - positive high viral load respiratory samples whereas between $0-21.1 \%$ for normal viral load samples. ${ }^{20}$ In contrast Eliseo Albert et al. yielded an excellent specificity and a fairly good overall sensitivity $(79.6 \%)$ in their study to evaluate the overall performance of RAD assay conducted at a point of care setting itself. ${ }^{21}$ Similarly, in our study the RAD tests exhibited a fairly higher overall sensitivity of $66.01 \%$ and remarkable specificity of $99.71 \%$ amid 18901 nasopharyngeal samples although the reference standard was based on clinical symptoms. The higher overall sensitivity in our study and the latter study might be attributed to the fact that these studies were carried out on the spot while the earlier studies evaluating RAD assays utilized either retrieved specimens, which were cryopreserved, or those carried out at central laboratories, or both. However, it is important to understand that direct comparison between studies is logically sceptical due to major differences in patients' clinical presentation and age, testing facilities, type of sample preparation and time at which the test was performed along with others. Thereby, this seems to be a favourable approach as faster and comparatively reliable results would have to be delivered for immediate screening in a point of care setting wherein large-scale testing was to be carried out on passengers coming from distant cities with unknown prevalence. European Centre of Disease Control (ECDC) recommends RAD tests in a high prevalence setting due to its high positive predictive value (PPV). This means a positive result in the RAD test is likely to indicate a true infection and need not be confirmed by RT - PCR and a negative test result would have to be confirmed by RT - PCR. A similar approach was adopted in our setting and all the passengers who were screened were coming from such cities which were considered as high prevalence zones. Concurrent findings were demonstrated by Manual Linares et al. in their study wherein they collected 255 nasopharyngeal swabs from symptomatic and asymptomatic patients who were tested 
with Panbio RAD testing kits. ${ }^{22}$ They concluded that RAD tests can be used as an effective substitute for RT - PCR in these types of patients to cut off delays and reduce the excessive labour costs caused by the use of PCRs.

\section{CONCLUSIONS}

This study illustrates a prompt initiative taken by the authorities wherein dental students were trained to perform the RAD tests in such a crucial time of urgency and thereby served as front liners to carry out this type of large-scale dynamic testing of passengers coming from different areas with unknown prevalence. Although RAD tests displayed a fairly low sensitivity, their ability to be highly specific, less time consuming, minimally technique sensitive, being inexpensive as compared to PCR assays and accurate in the initial days of infection which justifies their use in a public screening at such point of care settings, therefore, curbing the further spread of the disease.

\section{Limitation}

A major limitation of this study was that the reference standard was based on common clinical symptoms associated with SARS-CoV-2 rather than RT - PCR.

Data sharing statement provided by the authors is available with the full text of this article at jemds.com.

Financial or other competing interests: None.

Disclosure forms provided by the authors are available with the full text of this article at jemds.com.

The authors would like to acknowledge the tireless efforts of all the students, postgraduate residents, faculties, administrative staff, transport and food service staff and helper staff during the pandemic.

\section{REFERENCES}

[1] Hui DS, Azhar EI, Madani TA, et al. The continuing 2019 $\mathrm{nCoV}$ epidemic threat of novel coronaviruses to global health-The latest 2019 novel coronavirus outbreak in Wuhan, China. International Journal of Infectious Diseases 2020;91:264-6.

[2] Zhu N, Zhang D, Wang W, et al. A novel coronavirus from patients with pneumonia in China, 2019. New England Journal of Medicine 2020;382(8):727-33.

[3] Phelan AL, Katz R, Gostin LO. The novel coronavirus originating in Wuhan, China: challenges for global health governance. JAMA 2020;323(8):709-10.

[4] Li Q, Guan X, Wu P, et al. Early transmission dynamics in Wuhan, China, of novel coronavirus-infected pneumonia. New England Journal of Medicine 2020;382:1199-207.

[5] Guo YR, Cao QD, Hong ZS, et al. The origin, transmission and clinical therapies on coronavirus disease 2019 (COVID - 19) outbreak-an update on the status. Military Medical Research 2020;7(1):11.

[6] Astuti I, Ysrafil. Severe acute respiratory syndrome coronavirus 2 (SARS - CoV - 2): an overview of viral structure and host response. Diabetes \& Metabolic Syndrome 2020;14(4):407-12.
[7] Pathak, Neha. Coronavirus and COVID - 19: What You Should Know. WebMD, 17 Dec, 2020. www.webmd.com / lung / coronavirus.

[8] COVID - 19 Lockdown in India. Wikipedia, Wikimedia Foundation, 22 Jan, 2021. en.wikipedia.org / wiki / COVID - 19_lockdown_in_India.

[9] Government of India, Press Information Bureau., 2020. National Directives For COVID - 19 Management Continue To be in force throughout the country.: https://www.mha.gov.in/sites/default/files/17052020L ockdown_1.pdf [Accessed 24 January 2021].

[10] Indian Railways Issues Guidelines for 'Shramik Special' Trains amid COVID - 19 Lockdown. DNA India, May 3, 2020. www.dnaindia.com/india/report- indian - railways - issues - guidelines - for - shramik - special - trains - amid - covid - 19 - lockdown - 2823459.

[11] Government of India, Press Information Bureau., 2020. MHA Issues Standard Operating Protocol (SOP) to facilitate movement of persons by train.: https://www.mha.gov.in/sites/default/files/PR_MHASO PsforTravelofPersonsbyTrain_11052020.pdf [Accessed 24 January 2021].

[12] Kumar M. Ahmedabad Municipal Corporaion, Municipal Commisioner Order (Dt: 25 - 08 - 2020). (Notification No. GP/9/NVC/102020/SF-1/G).

[13] Rai MK. Unlock 4: Metro Services to Resume from Sept 7. Metro Rail News, 2 Sept, 2020. www.metrorailnews.in/ unlock - 4 - metro - services - to - resume - from - sept $7 \%$.

[14] Broberg E, Ciancio B, Ködmön C, et al. Options for the use of rapid antigen tests for COVID - 19 in the EU / EEA and the UK. [e-book] European Centre for Disease Prevention and Control, 2020. https://www.ecdc.europa.eu/sites/default/files/docum ents/Options - use - of - rapid - antigen - tests - for - COVID - 19.pdf [Accessed 24 January 2021].

[15] ETHealthworld. Rapid antigen test may be used to 'rule in' covid patients within 1 st 5 days of illness: study. ET HealthWorld. ETHealthworld.com, 4 Nov, 2020. health.economictimes.indiatimes.com/news/diagnostics /rapid - antigen - test - may - be - used - to - rule - in - covid - patients - within - 1st - 5 - days - of - illness study/79041749.

[16] https://www.icmr.gov.in/pdf/covid/strategy/Advisory_ for_rapid_antigen_test_14062020.pdf.

[17] SD Biosensor, Inc. Products - Standard Q COVID - 19 Ag, sdbiosensor.com/xe/product/7672.

[18] World Health Organization. Antigen - detection in the diagnosis of SARS - CoV - 2 infection using rapid immunoassays: interim guidance, 11 September, 2020. World Health Organization, 2020.

[19] Scohy A, Anantharajah A, Bodéus M, et al. Low performance of rapid antigen detection test as frontline testing for COVID - 19 diagnosis. Journal of Clinical Virology 2020;129:104455.

[20] Mak GC, Cheng PK, Lau SS, et al. Evaluation of rapid antigen test for detection of SARS - CoV - 2 virus. Journal of Clinical Virology 2020;129:104500.

[21] Linares M, Pérez - Tanoira R, Carrero A, et al. Panbio antigen rapid test is reliable to diagnose SARS - CoV - 2 infection in the first 7 days after the onset of symptoms. Journal of Clinical Virology 2020;133:104659. 
[22] Albert E, Torres I, Bueno F, et al. Field evaluation of a rapid antigen test (Panbio ${ }^{\mathrm{TM}}$ COVID - 19 Ag Rapid Test Device) for COVID - 19 diagnosis in primary healthcare centres.
Clinical Microbiology and Infection 2021;27(3):472.e2e10. 